EDITORIAL

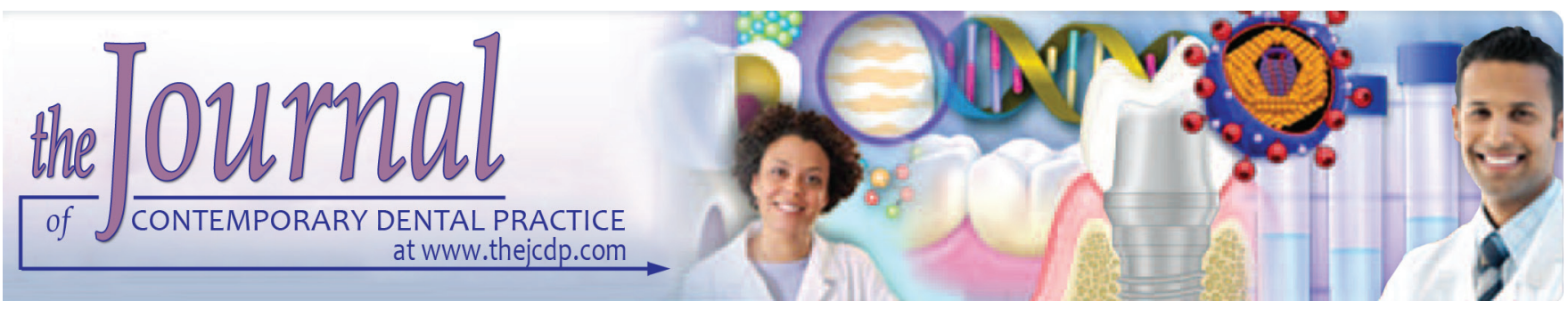

\title{
Multifaceted Role of Calcium in Cancer
}

\author{
${ }^{1}$ Gargi S Sarode, ${ }^{2}$ Sachin C Sarode, ${ }^{3}$ Shankargouda Patil
}

How to cite this article: Sarode GS, Sarode SC, Patil S. Multifaceted Role of Calcium in Cancer. J Contemp Dent Pract 2017;18(1):1-2

\section{Source of support: Nil}

Conflict of interest: None

\section{INTRODUCTION}

Role of calcium in bone remodeling and tooth remineralization is well known. However, calcium also plays a very imperative role in many biochemical reactions, which are essential for normal functioning of cells. The calcium associated tissue homeostasis encompasses activities like proliferation, cell death, cell motility, oxygen, and nutrient supply. Since many of these activities are linked to carcinogenesis process, it is quite conceivable to envisage calcium as one of the key performers in malignant transformation and progression.

The first and most significant characteristic feature of cancer cells is proliferation, which involves participation of various organelles and pathways. Calcium related proteins accountable for proliferation are mentioned in Table 1. Higher expression of these factors and proteins is responsible for increased proliferation rate of cells. All the activities encompass increase in cytoplasmic calcium due to calcium influx or calcium release or sustained endoplasmic reticulum calcium filling. ${ }^{1}$

Calcium is also known to have a major stake in mediating apoptosis, which has been proved in many original

\footnotetext{
1,2Department of Oral Pathology and Microbiology, Dr. D.Y. Patil Dental College and Hospital, Dr. D.Y. Patil Vidyapeeth, Pune Maharashtra, India

${ }^{3}$ Department of Maxillofacial Surgery and Diagnostic Sciences Division of Oral Pathology, College of Dentistry, Jazan University Jazan, Kingdom of Saudi Arabia.

Corresponding Author: Sachin C Sarode, Department of Oral Pathology and Microbiology, Dr. D.Y. Patil Dental College and Hospital, Dr. D.Y. Patil Vidyapeeth, Pune, Maharashtra, India Phone: +919922491465 e-mail: drsachinsarode@gmail.com
}

Table 1: Calcium related proteins and pathways responsible for cancer cell proliferation

\begin{tabular}{ll}
\hline Sl. no. & Proteins and pathways \\
\hline 1 & Sarco endoplasmic reticulum \\
2 & Golgi network secretory pathway \\
3 & Ca $^{2+}$-ATPases \\
4 & Inositol 1,4,5-trisphosphate receptor \\
5 & Ryanodine receptor \\
6 & Ca $^{2+}$ release channels of the endoplasmic reticulum (ER) \\
7 & Stromal interaction molecule \\
8 & T-type voltage-gated calcium channels \\
9 & Various Transient receptor potential (TRP)-members \\
\hline
\end{tabular}

studies and review articles. ${ }^{2}$ The calcium related initial events include cytoplasmic calcium overload either due to increased influx or release. Three important pathways mediate this: Mitochondrial, cytoplasmic and endoplasmic reticulum stress related. ${ }^{2}$ To evade apoptosis, cancer cells usually program themselves to decrease calcium influx into cytoplasm. ${ }^{3}$ Various mechanisms that can bring about this change are shown in Table 2.

Cell migration and invasion are again two important aspects of cancer cells that determine the aggressive behavior and metastatic potential. ${ }^{4}$ Calcium helps in migration and invasion of cancer cells by promoting focal adhesion turnover, enhancing contractile assembly and facilitating proteolysis of extracellular matrix. ${ }^{5}$ Calcium does this feast at molecular level with the help

Table 2: Calcium related mechanisms in apoptosis

\begin{tabular}{|c|c|}
\hline Sl. no. & Mechanisms \\
\hline 1 & $\mathrm{Bcl}-2$ related leakage of endoplasmic reticulum calcium \\
\hline 2 & $\begin{array}{l}\text { Inositol trisphosphate receptor-channel medicated } \\
\text { release of cytosolic and mitochondrial calcium }\end{array}$ \\
\hline 3 & $\begin{array}{l}\text { Overexpression of plasma membrane } \mathrm{Ca}^{2+} \text { permeable } \\
\text { channels }\end{array}$ \\
\hline 4 & $\begin{array}{l}\text { IP3R mediated surges of cytosolic calcium triggers } \\
\text { MPT and releases mitochondrial apoptosis factors }\end{array}$ \\
\hline 5 & $\begin{array}{l}\text { Nuclear factor of activated T cells nuclear factor of } \\
\text { activated T cells (NFAT) inhibition that ultimately } \\
\text { decreases expression of pro-apoptotic fas ligand }\end{array}$ \\
\hline
\end{tabular}


of calcineurin, CaMKII, proline-rich tyrosine kinase-2, $\mathrm{Ca}^{2+}$-dependent protease, calpain, which controls focal adhesion dynamics and S100 family of EF-hand calciumbinding proteins (especially S100A4) which promotes cell migration via interaction with cytoskeletal proteins, including actin. ${ }^{6}$

Neoangiogenesis is one of the decisive players in tumor progression. Many critical aspects of the complex process of angiogenesis are governed by calcium signals. ${ }^{7}$ Many growth factors associated with angiogenesis are linked with induction of calcium signaling that involves endothelial cell proliferation. Many therapeutic drugs like Carboxyamidotriazole have been recognized as potential antiangiogenic molecules that act via calcium signaling. ${ }^{8}$

Autophagy in cancer is generating an impact on translational front in many cancers. However, there is scarcity of literature on association of calcium in autophagy process. Høyer-Hansen et $\mathrm{al}^{9}$ demonstrated that various $\mathrm{Ca}^{2+}$ mobilizing stimuli, such as vitamin D3 compounds, ATP, thapsigargin and ionomycin, by inducing an increase in cytosolic calcium, activate the calcium/ calmodulin-dependent protein kinase-kinase and consequently inhibit mammalian target of rapamycin. So, the final consequence of the rise in cytosolic calcium is an induction of autophagy.

Statherin is the molecule present in the saliva that prevents the calcium phosphate precipitation leading to high concentration of free calcium and phosphate in saliva. It has been proposed that calcium present in saliva not only helps in remineralization of enamel but also helps in epithelial differentiation and homeostasis. In premalignant lesions and conditions, statherin levels are significantly reduced ${ }^{10}$ and statherin related calcium depletion in saliva has been proposed as one of the pathways of carcinogenesis mechanism in oral squamous cell carcinoma. $^{11}$

Calcium has multifaceted role in cancer initiation and progression. We believe that it is the only mineral, which is present so abundantly in the body and has such a vital role in carcinogenesis. Once a particular overexpressed calcium channel has been identified for a patient's cancer, then an agent directed against that particular channel could be added into the standard therapeutic combination of drugs. Properly applied, a calcium channel inhibition strategy could result in a long-term benefit and even perhaps longer patient survival.

\section{REFERENCES}

1. Metcalfe JC, Moore JP, Smith GA, Hesketh TR. Calcium and cell proliferation. British Medical Bulletin 1986; 42(4):405-412.

2. Nicotera $P$, Orrenius $S$. The role of calcium in apoptosis. Cell Calcium 1998 Feb-Mar; 23(2-3):173-180.

3. Rizzuto R, Pinton P, Ferrari D, Chami M, Szabadkai G, Magalhães PJ, Di Virgilio F, Pozzan T. Calcium and apoptosis: facts and hypotheses. Oncogene 2003 Nov;22(53): 8619-8627.

4. Lauffenburger DA, Horwitz AF. Cell migration: a physically integrated molecular process. Cell 1996 Feb;84(3):359-369.

5. Chen YF, Chen YT, Chiu WT, Shen MR. Remodeling of calcium signaling in tumor progression. J Biomed Sci 2013 Apr 17; 20:23.

6. Prevarskaya N, Skryma R, Shuba Y. Calcium in tumour metastasis: new roles for known actors. Nat Rev Cancer 2011 Jul;11(8):609-618.

7. Munaron L. Intracellular calcium, endothelial cells and angiogenesis. Recent Pat Anticancer Drug Discov 2006 Jan;1(1):105-119.

8. Munaron L, Genova T, Avanzato D, Antoniotti S, Fiorio Pla A. Targeting calcium channels to block tumor vascularization. Recent Pat Anticancer Drug Discov 2013 Jan 1;(8):27-37.

9. Høyer-Hansen M, Bastholm L, Szyniarowski P, Campanella M, Szabadkai G, Farkas T, Bianchi K, Fehrenbacher N, Elling F, Rizzuto R, et al. Control of macroautophagy by calcium, calmodulin-dependent kinase kinase-beta, and Bcl-2. Mol Cell 2007 Jan 26; 25(2):193-205.

10. Contucci AM, Inzitari R, Agostino S, Vitali A, Fiorita A, Cabras T, Scarano E, Messana I. Statherin levels in saliva of patients with precancerous and cancerous lesions of the oral cavity: a preliminary report. Oral Dis 2005 Mar;11(2):95-99.

11. Sarode SC, Sarode GS, Patil S. Role of statherin in oral carcinogenesis. Oral Oncol 2014;50(10):e55-e56. 